Article

\title{
Spatial Segregation, Redistribution and Welfare: A Theoretical Model
}

\author{
Tommaso Gabrieli \\ Bartlett School of Planning, University College London, WC1H ONN, UK; E-Mail: t.gabrieli@ucl.ac.uk
}

Submitted: 18 December 2015 | Accepted: 1 March 2016 | Published: 24 March 2016

\begin{abstract}
This paper develops a theoretical model focusing on the effect that different neighborhood compositions can have on the formation of individual beliefs about economic opportunities. Specifically we highlight two effects that spatial segregation may have: (1) it can efficiently separate the individual effort choices of highly and low productive individuals, (2) it may imply that the median voter imposes a level of redistribution that is inefficient from the aggregate point of view. The trade-off implies that segregated and non-segregated cities may present very similar levels of aggregate welfare. We employ this framework to discuss how the structure of cities can play a role in the determination of US-type and Europe-type politico-economic equilibria and the implications for planning policies.
\end{abstract}

\section{Keywords}

median voter; redistribution; spatial segregation; welfare

\section{Issue}

This article is part of the issue "Urban Forms and Future Cities", edited by Luca D'Acci (Erasmus University Rotterdam, The Netherlands), Tigran Haas (KTH Royal Institute of Technology, Sweden) and Ronita Bardhan (Indian Institute of Technology Bombay, India).

(C) 2016 by the author; licensee Cogitatio (Lisbon, Portugal). This article is licensed under a Creative Commons Attribution 4.0 International License (CC BY).

\section{Introduction}

A large body of research across disciplines describes the correlation between the extent of spatial segregationon the basis of many factors e.g. income or race-and the levels of income inequality and poverty. Typically spatial segregation is associated with very unequal economic outcomes, dramatic poverty levels, many social dimensions of deprivation and exclusion. ${ }^{1}$ According to standard economic theory, this pattern is not surprising as segregation can be explained as the spatial manifestation of economic inequality, where poverty can lead to segregation through market forces. If the poor can only afford "poor" neighborhoods, then poor people end up living in one place and the rich in another. Moreover, preferences for assimilation can re-enforce this outcome known as sorting, see for example Cheshire, Monastiri-

\footnotetext{
${ }^{1}$ A large literature documents the spatial patterns of segregation in the Western world, where deprived neighborhoods in most American and European cities are the typical examples. See for example OECD (1998), Musterd and Ostendorf (1998), and Kazepov (2004).
}

otis and Sheppard (2003).

We expect economic inequality and poverty to cause spatial segregation, but spatial segregation may in turn increase the extent of inequality, exacerbate poverty and possibly create spatial poverty traps at the neighborhood level ${ }^{2}$. A recent literature in economics pointed to various possible causes for the existence of urban spatial poverty traps in developed economies: peer effects $^{3}$, networks and information ${ }^{4}$, education and public goods ${ }^{5}$. Despite the empirical challenges in establishing a robust causal relationship from spatial segregation to

\footnotetext{
${ }^{2}$ A spatial poverty trap is defined as a situation where "geographic capital" (the physical, natural, social, political and human capital of an area) is low and poverty is high, partly as a result of geographic disadvantage. In other words, in a situation of spatial poverty trap, people leaving in a poor area do not have physical, social or human resources to escape poverty and improve their socio-economic condition. See Bird, Higgins and Harris (2010) for a review.

${ }^{3}$ See for example Durlauf (1996).

${ }^{4}$ See for example Zenou (2013).

${ }^{5}$ See for example the review of Fernandez (2001).
} 
poverty traps ${ }^{6}$, there are various channels by which urban segregation can negatively impact on social welfare ${ }^{7}$ and investigating the socio-economic effects of segregation remains an important question for policy.

Our paper contributes to this research question and to different strands of literature by focusing on the effect that different urban structures and neighborhood social compositions can have on the formation of individual beliefs about economic opportunities. More specifically, in our model individuals do not have perfect information about their economic opportunities (i.e. the return on effort) but can learn by observing aggregate outcomes in their local community. In this situation living in a poor community will have a negative impact on potentially productive individuals (people with a high return on effort), because they will generally believe economic opportunities to be limited and therefore exert low effort, thereby creating a self-fulfilling poverty trap. The opposite outcome could happen to lowly productive people living in a successful community, since they will believe the return on effort to be high and will therefore exert high effort, thereby helping their optimist belief to be self-fulfilled. This aspect of negative or positive neighborhood externality on effort choices is similar to models of peer and network effects. ${ }^{8}$

Our first contribution is to employ a micro-economic analysis to model the implications of different urban forms and of the extent of spatial segregation in a setup with neighborhood social externalities. ${ }^{9}$

Secondly, we also model the effect that individual beliefs have on preferences for redistribution and we contribute to a novel and growing literature which-

\footnotetext{
${ }^{6}$ Typically endogenous sorting and the unobserved individual variables create a natural econometric problem of endogeneity, where standard regression techniques of neighborhood economics outcomes against neighborhood social features would give biased results. Solutions have been found in large scale natural experiments or in advanced econometric techniques based on large data-sets. See Ross (2011) for an extended review on this topic.

7 The papers reviewed by Fernandez (2001) model various channels through which sorting is inefficient. For example, Benabou (1993) discusses the role of complementary skills, Benabou (1996) and Fernandez and Rogerson (1996) analyze the interaction between local school financing and the production of human capital.

9 This methodology can be considered as complementary to more traditional methodologies that have been used in the broad field of urban studies to address related questions, see for example Arbaci (2007), and Arbaci and Rae (2013) among others.

${ }^{8}$ See for example Durlauf (1996), Mookherjee, Ray and Napel (2010), and Zenou (2013).

${ }^{9}$ With this respect, our methodology can be considered as complementary to more traditional methodologies that have been used in the broad field of urban studies to address related questions, see for example Arbaci (2007), and Arbaci and Rae (2013) among others.
}

extending a long tradition in sociology and political science since De Tocqueville (1835) - focuses on the link between persistent differences in popular beliefs about the true extent of individual economic opportunities and social mobility and persistent differences in political outcomes. ${ }^{10}$ We extend this literature by analyzing the role played by urban structures in the formation of beliefs and we highlight two effects that spatial segregation may have: (1) it can efficiently separate the individual effort choices of highly and low productive individuals, (2) it may imply that the voted level of redistribution is too high or too low with respect to social welfare.

Thirdly, by developing a microeconomic model that jointly analyzes spatial segregation and politicoeconomic outcomes, we contribute to a recent and growing interdisciplinary literature that is introducing new mathematical formalizations in the study of urban forms and policy issues for urban planning. ${ }^{11}$ The rest of the paper is organized through an exposition of the theoretical model divided in three subsections and a final section with discussion and conclusions. All the technical proofs and the figures can be found in the final appendix. ${ }^{12}$

\section{Model}

\subsection{Residents and Production}

We model one city with two neighborhoods (or communities) $j=\{1,2\}$. The entire city is inhabited by a unit measure of residents $i$ who work, get paid by the amount that they produce, pay taxes, receive public transfers and consume the entire net income. The individual production function is: $y^{i}=k^{i}+\theta^{i} e^{i}$, where $k^{i}$ is a given stock of resources that the agent cannot influence (i.e. parents' wealth or "luck"), $\theta^{i}$ is the individual return on effort, $e^{i}$ is the individual level of exerted effort. Following the standard formalization in public economics started by Romer (1975), we assume a linear redistribu-

\footnotetext{
${ }^{10}$ Typically this literature has tried to explain the persistent difference between European-type welfare states and US-type laissez-faire societies through the role of cultural beliefs. See the theoretical models of Piketty (1995), Alesina and Angeletos (2005), Benabou and Tirole (2006) and Gabrieli (2010) on how multiple politico-economic equilibria (US-type vs Europe-type) with different beliefs are possible. See the empirical works of Fong (2001), Corneo and Gruner (2002), Alesina and La Ferrara (2005) on the evidence that such beliefs are strong determinants of the demand for redistribution. See the surveys of Alesina, Glaeser and Sacerdote (2001) and Keely (2002) for a documentation of the cross-country differences in beliefs on social mobility and individual opportunities.

${ }^{11}$ See for example the psycho-economical benefits-based models of D'Acci (2013) and D'Acci (2015) or the agent-based framework of Prunetti, Muzy, Innocenti and Pieri (2014).

12 Those technical results draw from the work of Gabrieli (2010).
} 
tion scheme where post-tax income equals $w^{i}=(1-\tau) y^{i}$ $+y$ and over-lined variables denote averages. ${ }^{13}$ For the sake of simplicity, we initially assume an individual utility function which is linear in income. ${ }^{14}$ As standard in the literature, we also assume a quadratic cost of effort to ensure that the utility is strictly concave in effort and hence there is a unique individual optimal effort choice. The individual utility function is therefore:

$$
u^{i}=w^{i}-\frac{a\left(e^{i}\right)^{2}}{2}
$$

where $a$ is the cost of effort.

We model that a fraction $\pi$ of the population has low "opportunities" $\theta_{L}$ and the remaining fraction $1-\pi$ has high "opportunities" $\theta_{H}$, where $\theta_{H}>\theta_{L}$. Individuals do not know their "true" opportunities, but may learn something in their neighborhood. We assume a simple learning mechanism: agents observe the average return on effort in the neighborhood, respectively labeled as $\theta_{1}$ and $\theta_{2}$, and expect this to be their return on effort. ${ }^{15}$

We then model segregation through a parameter $\lambda$ which is the fraction of $\theta_{L}$ agents living in community 1 and the fraction of $\theta_{H}$ agents living in community 2 , which implies that the fraction of $\theta_{L}$ agents leaving in community 1 is $p\left(\theta_{L}, 1\right)=\pi \lambda$ and symmetrically $p\left(\theta_{L}, 2\right)=\pi(1-\lambda), p\left(\theta_{H}\right.$, $1)=(1-\pi)(1-\lambda), p\left(\theta_{H}, 2\right)=(1-\pi) \lambda$. The expected (or average) opportunity in community 1 is therefore given by and the one in community 2 by:

$\theta_{1}(\lambda)=\left[\pi \lambda \theta_{L}+(1-\pi)(1-\lambda) \theta_{H}\right] /[\pi \lambda+(1-\pi)(1-\lambda)]$,

and the one in community 2 by:

$\theta_{2}(\lambda)=\left[\pi(1-\lambda) \theta_{L}+(1-\pi) \lambda \theta_{H}\right] /[\pi(1-\lambda)+(1-\pi) \lambda]$.

It is immediate to notice that $\theta_{1}$ and $\theta_{2}$ are symmetric with respect to $\lambda=0.5$. By computation, we obtain an

13 This specification simply implies that the income is transferred with a proportional tax rate from those richer than the average income to those poorer than the average.

14 Standard microeconomic analysis shows that in the case of linear utility a zero tax rate would maximize aggregate welfare and that the optimal tax rate would be positive and larger the more concave is the utility function. We will discuss the implications of a concave utility function later in the paper.

15 This implies that all people living in the same neighborhood have the same expectation over the return on effort. We model only two neighborhoods for the sake of simplicity. The results of our analysis would not change if there were many neighborhoods, or equally if people were learning the average return on effort in smaller communities, e.g. families or other groups. intuitive proposition showing that an increase in segregation increases the extent of income inequality between the two neighborhoods:

\section{Proposition 1: $\theta_{1}$ decreases in $\lambda$ and $\theta_{2}$ increases}

in $\lambda$.

Because of the symmetry of $\theta_{1}$ and $\theta_{2}$ with respect to $\lambda$ $=0.5$, we will only consider the case of $\lambda \in[0.5,1]$ in the rest of the analysis, with the intuitive feature that in this case an increase in $\lambda$ is equivalent to an increase in the degree of segregation. Therefore, in our analysis, as segregation increases, $\theta_{1}$ decreases and community 1 becomes progressively less productive, while exactly the opposite happens in community 2.

By the first order condition in (1) with respect to $e^{i}$, we find that the optimal effort exerted by an individual who lives in community $j$ is:

$$
e^{j}=\frac{(1-\tau) \theta_{j}}{a}
$$

Therefore, individual effort increases in the expected return on effort $\theta_{j}$ and decreases in the tax rate $\tau$. We then define the aggregate output produced in the city, net of the distortive effective of tax, as $\Gamma(\lambda)$, where this depends on the effort exerted in each community and on the true productivity:

$$
\begin{aligned}
& \Gamma(\lambda)=\pi \theta_{L}\left(\lambda \theta_{1}(\lambda)+(1-\lambda) \theta_{2}(\lambda)\right)+(1-\pi) \theta_{H}\left((1-\lambda) \theta_{1}(\lambda)+\right. \\
& \left.\lambda \theta_{2}(\lambda)\right) .
\end{aligned}
$$

We then obtain the following proposition showing the effect of segregation on aggregate output:

\section{Proposition 2: $\Gamma$ is increasing and convex in the degree of segregation $\lambda$.}

This result can be interpreted as the standard beneficial effect of information in reducing adverse selection: segregation efficiently separates the effort choices of individuals with different productivity and prevents that highly productive individuals exert lower than optimal effort.

\subsection{Redistribution}

Plugging the individual optimal effort (2) and the expression for net income $w^{i}$ into the utility function (1) we obtain an indirect utility as a function of $\tau$ :

$$
\begin{aligned}
& u^{i}(\tau)=(1-\tau) k^{i}+(1-\tau)^{2} \theta_{j}{ }^{2} / a+\tau \bar{k}+ \\
& \tau(1-\tau) \Gamma / a-(1-\tau)^{2} \theta_{j}{ }^{2} / 2 a .
\end{aligned}
$$


Assuming that $2 \theta^{2} \mathrm{~L}>\theta^{2} \mathrm{H}$, we can show that expression (3) is strictly concave in $\tau$ and that the individual ideal tax rate of an individual $i$, living in community $j$, can be obtained by the first order condition:

$$
\tau\left(k^{i}, \theta_{j}\right)=1-\frac{1-\frac{a\left(\bar{k}-k^{i}\right)}{\Gamma}}{\frac{\left(\theta_{j}\right)^{2}}{\Gamma}} .
$$

Assumption 1: $2 \theta^{2} L>\theta^{2} H$.

Proposition 3: Under assumption (1), each individual $i$ has a unique ideal rate of redistribution given by expression (4).

We notice that expression (4) is the result of two components. $\frac{a\left(\bar{k}-k^{i}\right)}{\Gamma}$ is the standard motive for redistribution-firstly discussed by Meltzer and Richard (1981) - where a lower relative endowment with respect to the average naturally increases the desired tax rate and whether progressive or regressive, such distributive goals must be traded off against distortions to the effort-elastic component of the tax base. Instead, $\left(\theta_{j}\right)^{2} / \Gamma$ is the motive from redistribution that derives from believing that individual productivity is below the average. ${ }^{16}$

Following the framework of Meltzer and Richard (1981), as standard in the related literature, we model

16 This component relates to the role of beliefs in "upper mobility" firstly highlighted by Benabou and Ok (2001). that the voted (or equilibrium) tax rate $\tau$ coincides with the median $\operatorname{tax} \tau^{\mathrm{M}}$, where in our case this is jointly identified by the distribution of $k$ and the values of $j$ and $\Gamma$ which, in turn, both depend on $\lambda$.

In order to understand the effect of segregation on the voted tax rate we proceed with a simple numerical analysis. We can think first about a case in which the endowment $k$ is homogenous across individuals and therefore $a\left(\bar{k}-k^{i}\right)=0$. Given $\theta_{L}=1, \theta_{H}=1.5$ and $\pi=0.6$, Figure 1 a shows that moving from no segregation $(\lambda=$ $0.5)$ to maximum segregation $(\lambda=1)$ would increase the ideal tax rate $\tau(\cdot, 1)$ of someone leaving in the poorer community, i.e. some with expected productivity $\theta_{1}$, from 0 to $25 \%$. If we then set $a\left(\bar{k}-k^{i}\right)=0.3$, Figure $1 \mathrm{~b}$ shows that moving from no segregation $(\lambda=0.5)$ to maximum segregation $(\lambda=1)$ would increase that ideal tax rate from $15 \%$ to $40 \%$. Repeating the numerical analysis for different parameters values, while assuring that $\tau \in(0,1)$, does not change the fact that $\tau(\cdot, 1)$ increases in the extent of segregation $\lambda$. Hence, by numerical analysis we obtain the following result:

\section{Proposition 4: The ideal tax rate of someone living in the poor community increases as the degree of segregation increases. Symmetrically, the ideal tax rate of someone living in the rich community decreases as the degree of segregation increases.}

In the case of homogenous endowments across individuals, $k k^{i}$ and therefore there are only two groups of voters: those in community 1 with expected productivity $\theta_{1}$ and those in community 2 with expected productivity $\theta_{2}$. In this case, it is therefore very easy to analyze the effect of segregation on the voted tax rate.

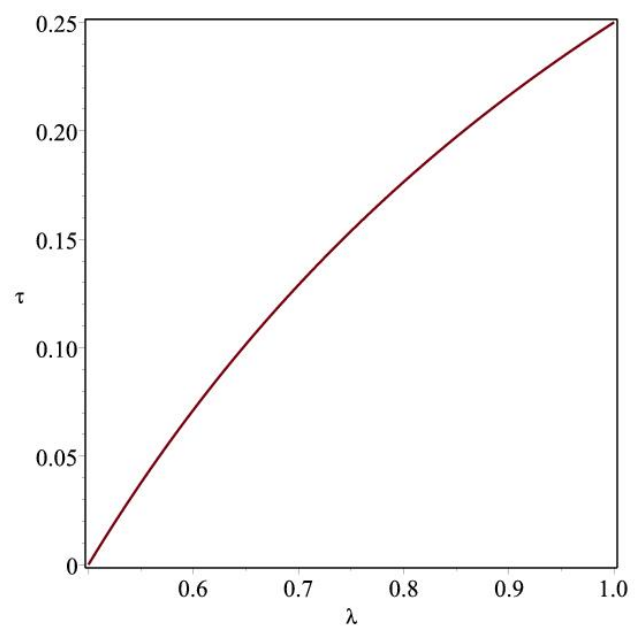

(a)

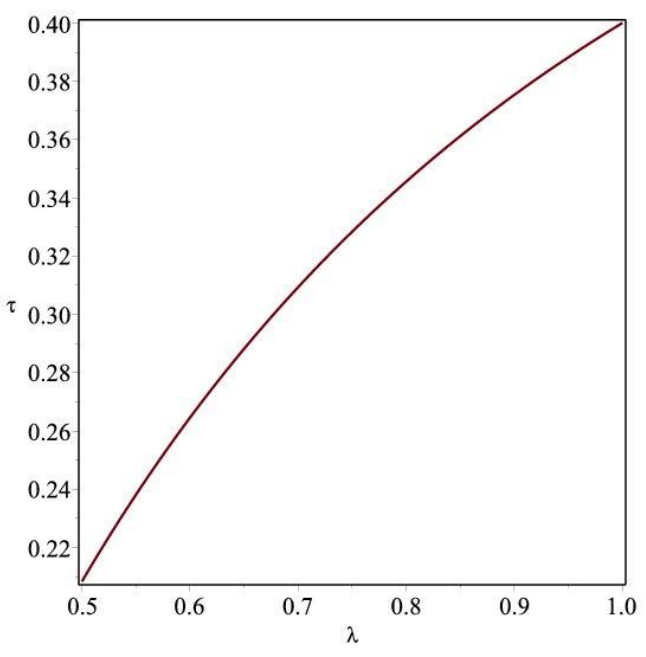

(b)

Figure 1. Effect of segregation on the ideal tax rate in community 1. Parameters: $\theta_{L}=1, \theta_{H}=1.5$ and $\pi=0.6,(\mathrm{~A}): a\left(\bar{k} k^{i}\right)$ $=0,(\mathrm{~B}): a\left(\bar{k} k^{i}\right)=0.3$. 
Proposition 5: In the case of homogenous endowments across individuals, if $\pi>0.5$ the voted tax rate increases as the degree of segregation increases, if $\pi<0.5$ the voted tax rate decreases as the degree of segregation decreases.

The previous proposition simply shows that with only two groups of voters the median voter belongs to the larger of the two groups and, therefore, as segregation makes each group respectively more and less pessimistic about productivity, the ideal tax rate of the median voter changes.

In the case of heterogeneous endowments across individuals, from expression (4) we notice that the median ideal tax rate is determined by the joint distribution of $\theta_{j}$ and $k^{i}$. In this case, changing the level of segregation does not generally have a monotonic effect on the voted tax rate, because the distribution of ideal tax rates changes with the level of segregation and the ideal tax rate may change discontinuously. ${ }^{17}$ In principle economic opportunities and endowments are likely to be jointly determined and correlated through intergenerational transfers. ${ }^{18}$ As mentioned in the introduction, a vast literature in urban economics shows that through the working of land and housing markets and because of homophily we generally expect a positive correlation between individual wealth and likelihood of living in more expensive neighborhoods. Therefore in our model we expect people living in the richer neighborhood to have larger endowments. Provided that those endowments are not too heterogeneous across the neighborhoods, the effect of segregation on the voted tax rate would still be the one described by Proposition 5.

Summarizing the analysis of redistribution, our modeling of segregation captures the situation of many cities where large inequality of opportunities is correlated with wealth and income inequality across different neighborhoods of the city. The effect of segregation that we have analyzed is to separate the voters into two groups with different opinions about the return on effort, i.e. the scope for social mobility. Depending on the underlying distribution of economic opportunities (the value of $\pi$ ) Proposition 5 shows that one group of voters will be the majority and impose its ideal tax rate.

From the previous analysis there are two possible dynamics describing the effects of an increase of the degree of segregation in a city. The first one is one in which the disadvantage group, the one with $\theta_{L}$, is in the majority and more segregation could increase the prevailing tax rate by making this majority group more pessimistic about economic opportunities. This could be interpreted as the dynamic in cities with a small rich

\footnotetext{
17 See chapter II of Gabrieli (2009) for a detailed analysis of this case.

${ }^{18}$ A full characterization of that dynamic process is beyond the scope of this paper and a related analysis can be found in Gabrieli (2012).
}

area and where the middle and lower class live alongside in larger and more diverse areas; in this case greater segregation would increase the poor population in the poorer area and increase their desire for redistribution.

The second dynamic is one in which the disadvantage group is in the minority and more segregation decreases the prevailing tax rate by making the majority richer group more optimistic about economic opportunities. This could be interpreted as the dynamic in cities with small deprived areas and where more segregation makes the middle and upper class less empathic with those poor areas.

Although in our model we do not explicitly model land or housing markets, referring to standard theory we would expect wealthier individuals to be located in the richer area. Including intergenerational transfers would therefore imply a correlation between productivity and endowments and would further separate the two groups. This can be interpreted as the effect of private housing markets where the best neighborhoods can only be afforded by the wealthiest. In this case we could even have a situation where the poorest are so excluded that some of them do not vote. ${ }^{19}$ If this is the case more segregation could decrease the level of redistribution because some of the voters among the disadvantage group may not vote and those in the wealthier neighborhood may become the majority group.

\subsection{Welfare}

Given the effects of segregation on the voted tax rate, it is now a natural question to analyze the effect of segregation on the aggregate welfare of the city. For the sake of simplicity, we begin the analysis by using a standard aggregate welfare function equal to the average utility, i.e. the expected value of (3) in the economy, conditional on the degree of segregation $\lambda$. Noticing that the expected value of $\left(\theta_{j}\right)^{2}$ for the economy is given by expression (3) we find that the expected value of the individual utility, i.e. the expression for aggregate welfare, given the degree of segregation:

$$
E\left(u^{i}\right)=\bar{k}+\tau\left(1-\tau(\lambda)^{2}\right) \Gamma(\lambda) / 2 a
$$

As it is always with linear utility, a zero tax rate maximizes aggregate welfare because in the expression redistribution does not have benefits, being a pure transfer of resources between citizens that all weight equally for aggregate welfare, but at the same time redistribution has a social cost because it decreases optimal effort. We will also discuss the case of concave welfare function, where the welfare-maximizing tax rate is pos-

\footnotetext{
${ }^{19}$ See Benabou (2000) for a related analysis of the effects of extreme inequality on the voting behavior of the poor.
} 
itive or more simply a Rawlsian welfare function where a positive tax rate maximizes the utility of the most disadvantage group.

We notice that in expression (5) the value of $\lambda$ affects both the prevailing tax rate $\tau$ and the aggregate product of effort $\Gamma$. Proposition 2 has illustrated that $\Gamma$ monotonically increases with the degree of segregation and Proposition 5 has shown that the effect of segregation is monotonic on the voted tax rate $\tau$. For this reason, the effect of segregation on aggregate welfare (5) is not a priori clear and there can be a trade-off effect of segregation in the case in which increasing segregation increases (or decreases) the voted tax rate above (or below) the welfare maximizing level, while it surely increases the component $\Gamma$. A full mathematical characterization of the effect of $\lambda$ on expression (5) is beyond the scope of this paper, but can be found in the results of Gabrieli (2010). The results show that in the case in which the tax rate increases with segregation, the overall effect of segregation on the expression of ex-ante utility (5) is to either monotonically decrease welfare or monotonically decrease it up to a point and then monotonically increase it.

This result implies that either no segregation $(\lambda=$ $1 / 2)$ or full segregation $(\lambda=1)$ can maximize aggregate welfare (5). We present some numerical examples for this general property.

Figure 2a shows a case with homogenous endowments and Figure $2 b$ shows a case with heterogenous endowments and discontinuous change of the median voter. Figure 3 shows a case with concave utility function where the welfare maximizing tax rate would be positive. In the figures we notice that the parameters have been chosen in such a way that no segregation $(\lambda$ $=1 / 2$ ) or full segregation $(\lambda=1)$ are equally optimal for aggregate welfare. ${ }^{20}$ Numerical exercises show clearly

${ }^{20}$ While the set of parameters such that both $\lambda=1 / 2$ and $\lambda=1$

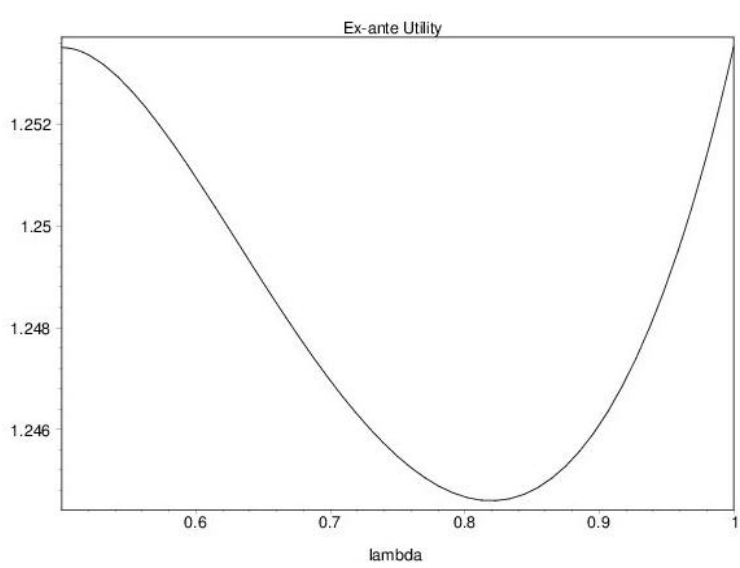

(a) that by increasing the underlying heterogeneity among the groups, i.e. increasing $\tau$ or increasing the difference $\theta_{H}-\theta_{L}$, implies that segregation is relatively more beneficial, i.e. the value of (5) for $\lambda=1$ increases relatively to the value of (5) for $\lambda=1 / 2$.

The intuition behind this result is that increasing the degree of segregation has a trade-off effect on welfare: on one hand it improves the allocation of individual effort (increasing $\Gamma$ ) but on the other hand it may raise redistribution beyond the efficiency level, therefore (5) does not increase monotonically in $\lambda$. Secondly, the convexity of $\Gamma$ (Proposition 2) implies that (5) is either monotonically decreasing or quasi-convex, hence the two corner welfare-maxima. The possibility of both no segregation and full segregation being welfare-maxima can be interpreted as indicating that cities with small differences in the parameters $\pi, \theta_{L}, \theta_{H}$ may find very different levels of segregation to be optimal.

\section{Conclusion}

In this paper we developed a microeconomic model of the effects that different urban forms and sizes of neighborhoods (or smaller community groups) can have on the joint dynamics of individual effort choices and prevailing rates of redistribution by explicitly modeling the role that urban forms have for the determination of societal beliefs regarding economic opportunities. With the model we were able to quantify the implications of different degrees of segregation on politico-economic variables: aggregate output, prevailing rate of redistribution and aggregate welfare.

are global maxima of (5) has zero measure, it follows that there are sets with positive measure such that both $\lambda=1 / 2$ and $\lambda=1$ are local maxima. Also in the case of concave utility we can equally have examples where no segregation is welfare maximizing.

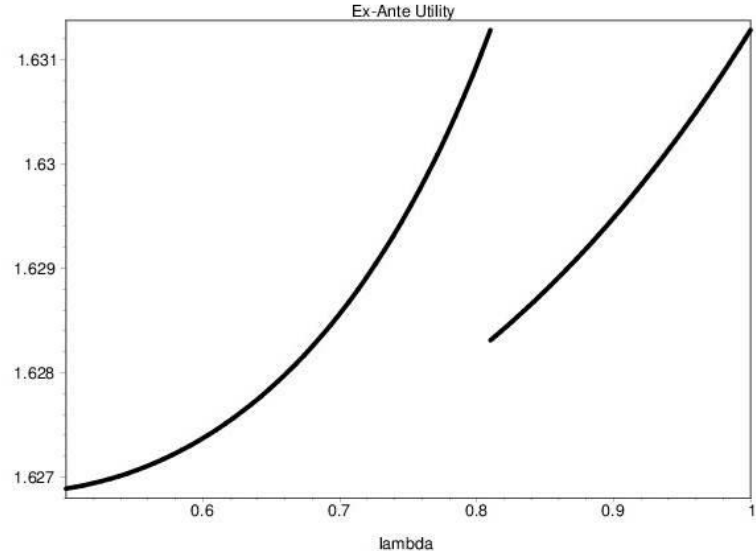

(b)

Figure 2. Effect of segregation on aggregate welfare (multiple optima). (a) Parameters: $\theta_{L}=1, \theta_{H}=1.5, \pi=0.76, a=0.5,-$ $\left.k^{i}\right)=0$. (b) Parameters: $\theta_{L}=1, \theta_{H}=1.5, \pi=0.8,\left(\bar{a}=0.4, a\left(\bar{k} k^{i}\right)=0.4\right.$. 


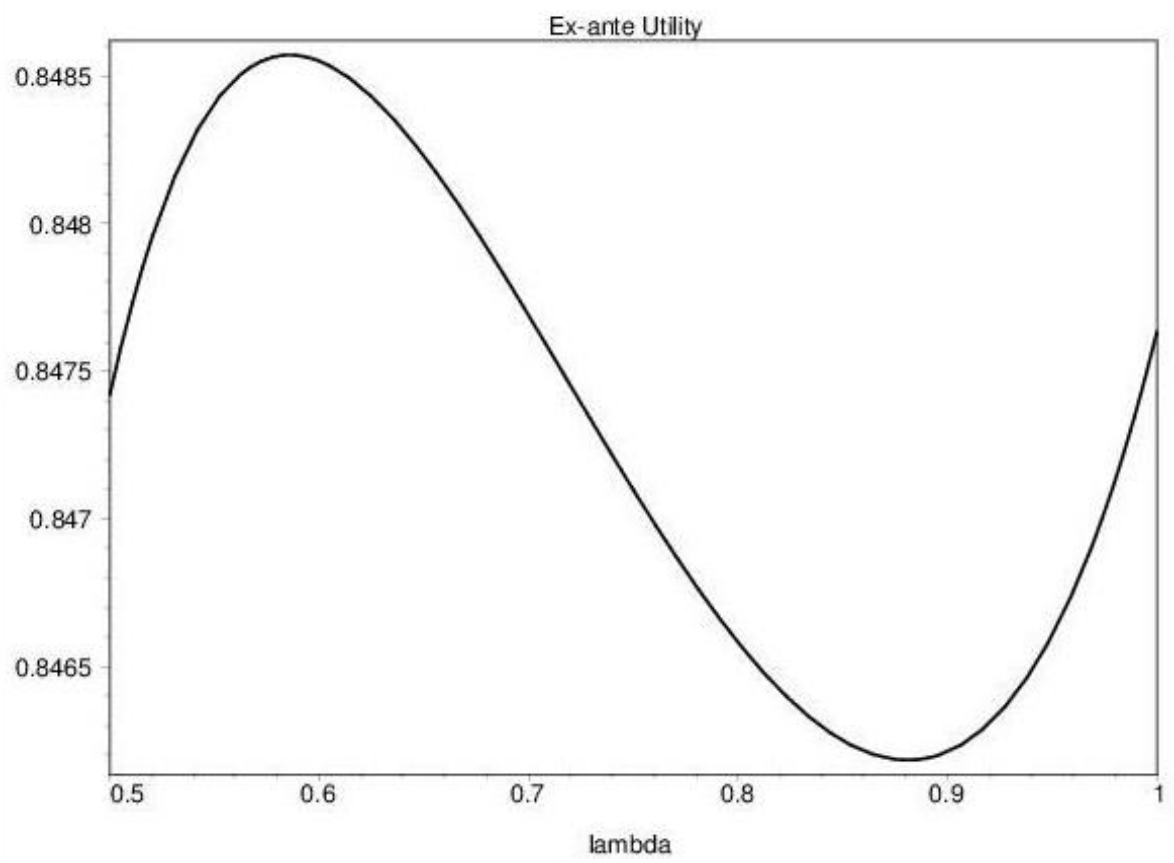

Figure 3. Case of concave utility function. Parameters: $\theta_{L}=1, \theta_{H}=1.5, \pi=0.8, a=0.4, a\left(\bar{k} k^{i}\right)=0.4$

According to the model, an increase in the degree of segregation implies that beliefs about economic opportunities become more heterogeneous across different neighborhoods, with people in poor neighborhoods having pessimistic beliefs about the return on effort and the scope for social mobility, while people in richer neighborhoods hold opposite beliefs. This separating effect is beneficial to aggregate output simply because, on average, individuals become better informed about their return on effort and therefore effort is more efficiently allocated between people with high and low opportunities. $^{21}$

Although efficient from the perspective of aggregate output maximization, segregation increases income inequality across neighborhoods and this implies other effects. Allowing for intergenerational transfers would imply that individual endowments and return on effort are to some extent correlated ${ }^{22}$ and this would further increase the extent of both income and wealth inequality across neighborhoods. Moreover, private housing markets where high bids from wealthy individuals can outbid poorer individuals would, in turn, imply that a modest initial degree of segregation can progressively increase over time through the implied wealth and income inequality that segregation fosters.

The model then shows that income inequality naturally increases the desired tax rate of poor people through the well-known Meltzer and Richard (1981)

${ }^{21}$ This beneficial effect would generally be more limited in models with complementary skills, see for example Benabou (1993).

${ }^{22}$ For example through investments in the human capital of children. motive for redistribution and therefore the unequal effects of segregation could in principle be corrected by higher voted redistribution. Nevertheless, in the model beliefs about economic opportunities which are formed in the neighborhood are also shown to affect the desired tax rate. The interaction of those two motives for redistribution is studied through numerical examples and segregation is shown to generally increase the desired tax rate of those living in poorer neighborhoods and decrease the desired tax rate of those living in richer neighborhoods. ${ }^{23}$

Although the effect of segregation on the individual ideal tax rate is quite clear to quantify, the determination of the prevailing tax rate imposed by the median voter is less clear because of discontinuous changes in the distribution of ideal tax rates. Two different dynamics are shown to be possible. In one possible dynamic, the majority of the population lives in the poorer neighborhood and more segregation increases the prevailing tax rate by making this majority group more pessimistic about economic opportunities, thus partially correcting the extent of income inequality. In a second possible dynamic, the majority of the population lives in the wealthier neighborhood and more segregation decreases the prevailing tax rate by making the majority group more optimistic about economic opportunities, thus contributing to even more unequal economic outcomes. The prevailing dynamic therefore depends on the urban form. The first one would be the case in cities with a small exclusive rich areas and where the middle and lower class live alongside in a

23 This is in line with the empirical findings of Bailey, Gannon, Kearns, Livingston and Leyland (2013). 
larger and more diverse areas; the second one would be the case in cities with small very deprived areas and where the middle and upper class live alongside in a larger areas.

Finally, by taking into account the joint effect of segregation on aggregate output and redistribution we analyze aggregate welfare. With this respect, a critical variable is represented by the definition of welfare function, where it is a standard result of microeconomics that the more concave the welfare function is then the larger the welfare-maximizing tax rate is, just like it would be the case with a Rawlsian welfare function that aims to maximizes the utility of the most disadvantage group. Despite the specific welfare function, we find that increasing the degree of segregation generally has a trade-off effect on welfare since, on the one hand, it improves the allocation of individual effort but, on the other hand, it may increase (or decrease) redistribution away from the efficient level. This trade-off effect implies that both no segregation and full segregation can be welfare-optimal for the same city and that small differences in the heterogeneity of the initial distribution of opportunities may justify very different levels of segregation.

This final result may be used to interpret the documented lower redistribution rate in the US relative to European countries, where societies with similar initial "parameters" may find different levels of segregation to be optimal. In particular, the lower taxation in the US may be explained by a median voter that lives in a wealthier community and may overestimate her own abilities. Although stuck in different planning and political outcomes, the two societies may have similar levels of welfare. ${ }^{24}$

Our results have interesting implications for the analysis of planning policies. We show that the effect that different urban forms and neighborhoods social mixes have on voted redistribution has large quantitative effects on social welfare and therefore this effect should be accounted for in policy analysis. We also show that because the effect of segregation on voted redistribution is not monotonic, also the effect of segregation on welfare is generally not monotonic. Never-

\footnotetext{
${ }^{24}$ Despite the fact that modeling a unique redistribution rate is a natural way to study different attitudes towards redistribution across countries, more specific city-level taxation mechanisms could also be studied. For example one may consider an alternative system imposing different levels of taxes for residents in different neighborhoods. One could also contrast this system to a more market-based redistribution mechanism based on subsidized land or house prices. In the present model even with different types of redistribution mechanism we would still have the trade-off effect of segregation on welfare, because segregation would still improve effort allocations but possibly raise redistribution over the optimal level. Nevertheless different redistribution mechanisms would generally give different quantitative results. We thank an anonymous referee for this interesting suggestion for future research.
}

theless we show that as long as the ideal rate of redistribution is positive, given land and housing market forces that naturally push towards full segregation, planning policies that preserve socially mixed neighborhoods can maximize welfare.

\section{Acknowledgments}

The initial idea of this model was born while the author was completing his PhD at The University of Warwick researching on the topic of redistribution under incomplete information; the author is grateful to Herakles Polemarchakis for early discussions. The author also wishes to thank Gabriel Ahlfeldt, Olmo Silva, Danny Ben-Shahar, Anupam Nanda, Nikolaos Georgantzis, three anonymous referees as well as seminar participants at University of Reading, AREUEA International Conference 2014 and ERSA Congress 2015 for precious comments and discussions at different stages of the project.

\section{Conflict of Interests}

The author declares no conflict of interests.

\section{References}

Alesina, A., \& Angeletos, G.-M. (2005). Fairness and redistribution: US versus Europe. American Economic Review, 95, 960-980.

Alesina, A., Glaeser, E., \& Sacerdote, B. (2001). Why doesn't the US have a European-type welfare state? Brookings Papers on Economic Activity, 2, 187-277.

Alesina, A., \& La Ferrara, E. (2005). Preferences for redistribution in the land of opportunities. Journal of Public Economics, 89(5/6), 897-931.

Arbaci, S. (2007). Ethnic segregation, housing systems and welfare regimes in Europe. European Journal of Housing Policy, 7(4), 401-433.

Arbaci, S., \& Rae, I. (2013). Mixed-tenure neighbourhoods in London: Policy myth or effective device to alleviate deprivation? International Journal of Urban and Regional Research, 37(2), 451-479.

Bailey, N., Gannon, M., Kearns, A., Livingston, M., \& Leyland, A. H. (2013). Living apart, losing sympathy? How neighbourhood context affects attitudes to redistribution and to welfare recipients," Environment and Planning A, 45(9), 2154-2175.

Benabou, R. (1993). Workings of a city: Location, education, and production. The Quarterly Journal of Economics, 108(3), 619-652.

Benabou, R. (1996). Equity and efficiency in human capital investment: The local connection. Review of Economic Studies, 63(2), 237-264.

Benabou, R. (2000). Unequal societies: Income distribution and the social contract. American Economic Review, 90(1), 96-129. 
Benabou, R., \& Ok, E. A. (2001). Social mobility and the demand for redistribution: The POUM hypothesis. The Quarterly Journal of Economics, 116(2), 447-487.

Benabou, R., \& Tirole, J. (2006). Belief in a just world and redistributive politics. Quarterly Journal of Economics, 121, 699-746.

Bird, K., Higgins, K., \& Harris, D. (2010). Spatial poverty traps (Odi working paper 321). London: ODI. Retrieved from www.odi.org/resources/docs/5514.pdf

Cheshire, P., Monastiriotis, V., \& Sheppard, S. (2003). Income inequality and residential segregation: Labour market sorting and the demand for positional goods. In R. Martin \& P. S. Morrison (Eds.), Geographies of labour market inequality. London: Routledge.

Corneo, G., \& Gruner, H. P. (2002). Individual preferences for political redistribution. Journal of Public Economics, 83(1), 83-107.

D'Acci, L. (2013). Simulating future societies in Isobenefit cities: Social isobenefit scenarios. Futures, 54, 3-18.

D'Acci, L. (2015). Mathematize urbes by humanizing them. Cities as isobenefit landscapes: Psychoeconomical distances and personal isobenefit lines. Landscape and Urban Planning, 139, 63-81.

De Tocqueville, A. (1835). De la democratie en Amerique. Paris.

Durlauf, S. N. (1996). A theory of persistent income inequality. Journal of Economic Growth, 1(1), 75-93.

Fernandez, R. (2001). Sorting, education and inequality (NBER Working Papers 8101). Cambridge, MA: National Bureau of Economic Research, Inc.

Fernandez, R., \& Rogerson, R. (1996). Income distribution, communities, and the quality of public education. The Quarterly Journal of Economics, 111(1), 135-164.

Fong, C. (2001). Social preferences, self-interest, and the demand for redistribution. Journal of Public Economics, 82(2), 225-246.

Gabrieli, T. (2009). Redistributive politics under optimally incomplete information (Ph.D. thesis). University of Warwick, UK.

Gabrieli, T. (2010). Diverse societal beliefs and redistributive policies, but equal welfare: The trade-off effect of information (Discussion Paper N. 10/04). London: City University of London, Department of Economics. Retrieved from http://www.city.ac.uk/_data/ assets/pdf_file/0007/73807/1004.pdf

Gabrieli, T. (2012). Inequality, intergenerational mobility and redistributive policies under endogenous information. The Journal of Economic Asymmetries, 9(1), 23-49.

Kazepov, Y. (2004). Cities of Europe: Changing contexts, local arrangements, and the challenge to urban cohesion. Malden, MA: Blackwell.

Keely, L. C. (2002). Mobility and fertility. University of Wisconsin-Madison. Unpublished manuscript.

Meltzer, A. H., \& Richard, S. F. (1981). A rational theory of the size of government. Journal of Political Economy, 89, 914-927.

Mookherjee, D., Ray, D., \& Napel, S. (2010). Aspirations, segregation, and occupational choice. Journal of the European Economic Association, 8(1), 139-168.

Musterd, S., \& Ostendorf, W. J. M. (1998). Urban segregation and the welfare state: Inequality and exclusion in western cities. London and New York: Routledge.

OECD. (1998). Integrating distressed urban areas. Paris: OECD Publishing.

Piketty, T. (1995). Social mobility and redistributive politics. Quarterly Journal of Economics, 110, 551-584.

Prunetti, D., Muzy, A, Innocenti, E., \& Pieri, X. (2014). Utility-based multi-agent system with spatial interactions: The case of virtual estate development. Computational Economics, 43(3), 271-299.

Romer, T. (1975). Individual welfare, majority voting, and the properties of a linear income tax. Journal of Public Economics, 4(2), 163-185.

Ross, S. L. (2011). Social interactions within cities: Neighborhood environments and peer relationships. In N. Brooks, K. Donaghy, \& G.-J. Knaap (Eds.), The Oxford handbook of urban economics and planning. Oxford: Oxford University Press.

Zenou, Y. (2013). Spatial versus social mismatch. Journal of Urban Economics, 74(C), 113-132.

\section{About the Author}

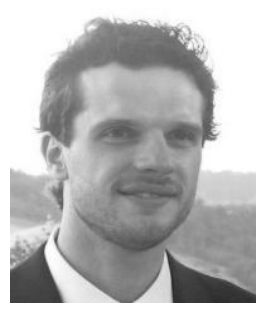

\section{Dr. Tommaso Gabrieli}

Tommaso Gabrieli is a lecturer in Real Estate at the Bartlett School of Planning, UCL. An economist by training and inspired by the Ambrosian tradition of social welfare, Tommaso has a strong interest in the socio-economic dynamics of cities, especially the extent of social mobility, the existence of poverty traps and the relative policy implications. His current research focuses on the links between spatial segregation and poverty traps, the application of game theory and real options to real estate valuation and policy, as well as work on behavioural economic theory and asset pricing. 
Appendix. Proofs.

\section{Proof of Proposition 1}

The monotonic behavior is immediately proved from the computation of the first derivative with respect to $\lambda$ :

$$
\begin{aligned}
& \frac{\partial \theta_{1}(\cdot)}{\partial \lambda}=-\frac{\pi(1-\pi)\left(\theta_{H}-\theta_{L}\right)}{(2 \pi \lambda+1-\lambda-\pi)^{2}}<0, \\
& \frac{\partial \theta_{2}(\cdot)}{\partial \lambda}=\frac{\pi(1-\pi)\left(\theta_{H}-\theta_{L}\right)}{(2 \pi \lambda-\lambda-\pi)^{2}}>0 .
\end{aligned}
$$

\section{Proof of Proposition 2}

In order to prove the monotonicity, it is enough to compute the expression of the first derivative of $\Gamma$ with respect to $\lambda$ :

$$
\begin{aligned}
& \frac{\partial \Gamma}{\partial \lambda}=\pi \theta_{L} \frac{\partial\left(\lambda \theta_{1}(\lambda)+(1-\lambda) \theta_{2}(\lambda)\right)}{\partial \lambda}+(1-\pi) \theta_{H} \frac{\partial\left((1-\lambda) \theta_{1}(\lambda)+\lambda \theta_{2}(\lambda)\right)}{\partial \lambda}= \\
& \pi \theta_{L}\left(-\frac{\pi(\pi-1)^{2}\left(\theta_{H}-\theta_{L}\right)(2 \lambda-1)}{(2 \pi \lambda+1-\lambda-\pi)^{2}(2 \pi \lambda-\lambda-\pi)^{2}}\right)+(1-\pi) \theta_{H}\left(-\frac{\pi^{2}(\pi-1)\left(\theta_{H}-\theta_{L}\right)(2 \lambda-1)}{(2 \pi \lambda+1-\lambda-\pi)^{2}(2 \pi \lambda-\lambda-\pi)^{2}}\right)= \\
& \frac{\pi^{2}(1-\pi)^{2}\left(\theta_{H}-\theta_{L}\right)^{2}(2 \lambda-1)}{(2 \pi \lambda+1-\lambda-\pi)^{2}(2 \pi \lambda-\lambda-\pi)^{2}}
\end{aligned}
$$

which is $\geq 0$ for $\lambda \geq 1 / 2$.

In order to prove the convexity, it is useful to compute the expression of the second derivative of $\Gamma$ with respect to $\lambda$ :

$$
\frac{\partial^{2} \Gamma}{(\partial \lambda)^{2}}=\frac{2 \pi^{2}(1-\pi)^{2}\left(\theta_{H}-\theta_{L}\right)^{2}(1+12 \pi \lambda(1-\lambda)(1-\pi)-3 \pi(1-\pi)-3 \lambda(1-\lambda))}{(\pi \lambda+(1-\lambda)(1-\pi))^{3}(\pi(\lambda-1)+\lambda(\pi-1))^{3}} .
$$

The expression is positive as it can be proved that the term $(1+12 \pi \lambda(1-\lambda)(1-\pi)-3 \pi(1-\pi) 3 \lambda(1-\lambda))($ call this $X)$ is strictly positive. To see this, compute the first derivative with respect to $\lambda$ which is equal to $3(2 \pi-1)^{2}(2 \lambda-1)$ and therefore positive. Hence the term $X$ increases in $\lambda$; it is immediate that $X$ is equal to zero for the smallest value of $\lambda$, i.e. $\lambda=1 / 2$. Therefore for any value of $\pi$ and $\lambda, X$ is positive.

\section{Proof of Proposition 3}

The second derivative of the objective function (3) is equal to:

$$
\frac{\partial^{2} u^{i}(\cdot)}{\partial \tau}=\frac{-2 \Gamma+\left(\theta_{j}\right)^{2}}{a}
$$

The condition stated by Assumption 1 is sufficient for the expression to be strictly negative as the maximum value that $\theta^{2}$ can take is $\theta^{2} H$ and the minimum value that $2 \Gamma$ can take is $2 \theta^{2} L$.

\section{Proof of Proposition 4}

Proved by the numerical analysis reported in Figure 1. 


\section{Proof of Proposition 5}

If $\pi>1 / 2$, since $\lambda \geq 0.5$, the majority of the population is the group of $\theta_{L}$ agents living in community 1 , i.e. $p(\theta\llcorner, 1)=\pi \lambda$ $>0.5$. Their ideal tax rate $\tau\left(;, \theta_{1}\right)$ increases in $\lambda$ by the previous proposition. Symmetrically, if $\pi<1 / 2$, since $\lambda \geq 0.5$, the majority of the population is the group of $\theta_{H}$ agents living in community 2, i.e.

$p\left(\theta_{H}, 2\right)=(1-\pi)(1-\lambda)>0.5$. Their ideal tax rate $\tau\left(; \theta_{2}\right)$ decreases in $\lambda$ by the previous proposition. 